\title{
Fecal Calprotectin Levels in Patients with Colonic Polyposis
}

\author{
Raffaele Pezzilli • Alessandra Barassi - Antonio M. Morselli Labate • \\ Sergio Finazzi · Lorenzo Fantini · Giuseppe Gizzi • \\ Milvia Lotzniker · Valeria Villani · Gianvico Melzi d'Eril • \\ Roberto Corinaldesi
}

Received: 27 November 2006/ Accepted: 6 March 2007/Published online: 28 April 2007

(C) Springer Science+Business Media, LLC 2007

\begin{abstract}
Context The usefulness of stool calprotectin determination in diagnosis of inflammatory disease of the colon has been reported; information about its usefulness for patients with polyposis are scarce, however.

Objective To evaluate the significance of stool calprotectin concentrations for patients affected by colonic polyposis.

Patients Sixty-three consecutive patients (35 males, 28 females, mean age 60.3 years, range $39-78$ years) were enrolled: 26 patients (41.3\%) with polyps, 17 patients (27.0\%) with asymptomatic diverticular disease, and 20 subjects (31.7\%) with normal endoscopic appearance of the colon.

Results Stool calprotectin concentrations were $17.4 \pm 24.5 \mu \mathrm{g} \mathrm{g}^{-1}$ for patients with colonic polyposis, significantly higher than concentrations for patients with diverticulosis $\left(7.1 \pm 5.7 \mu \mathrm{g} \mathrm{g}^{-1} ; P=0.026\right)$ or for patients with normal appearance of the colon (calprotectin $6.0 \pm 5.8 \mu \mathrm{g} \mathrm{g}^{-1} ; P=0.003$ ). For patients with a single polyp, stool calprotectin concentrations were similar to those for patients with multiple polyps. Calprotectin fecal concentrations for patients with sessile polyps and those
\end{abstract}

R. Pezzilli ( $₫)$ · A. M. Morselli Labate ·

L. Fantini · G. Gizzi · V. Villani - R. Corinaldesi

Department of Internal Medicine and Gastroenterology,

Sant'Orsola-Malpighi Hospital, University of Bologna,

Via Massarenti, 9, Bologna 40138, Italy

e-mail: pezzilli@aosp.bo.it

A. Barassi · G. Melzi d'Eril

Department of Medicine, Surgery and Dentistry,

University of Milan, Milan, Italy

S. Finazzi · M. Lotzniker

Central Laboratory, Legnano Hospital, Legnano, Italy with flat polyps were not significantly different. Calprotectin concentrations were not significantly related to the size of the polyps.

Conclusion Our data show that colonic polyposis may cause an increase in stool calprotectin values and that these colonic lesions should be suspected when elevated stool calprotectin concentrations are found.

Keywords Calcium-binding proteins - Colonic polyps Colonoscopy · Diverticulum · Colon · Leukocyte L1 Antigen Complex

\section{Introduction}

Colorectal neoplasia is one of the most common malignancies in the western world. The lifetime risk of colorectal cancer in the US population is $5-6 \%$. Over $50 \%$ of the population will develop an adenomatous polyp by the age of 70 years, even if only one tenth of these will proceed to cancer [1]. Colon cancer detection at an early stage and the possibility of identifying susceptible individuals could result in reduced mortality from this neoplasia. Early recognition and removal of polyps currently has a significant impact on reducing deaths from colon cancer [2]. There are several accepted screening methods, including fecal occult blood testing, sigmoidoscopy, double contrast barium enema, virtual colonoscopy, and optical colonoscopy [3, 4] but none is completely specific, sensitive, or reliable [5]. It has also been demonstrated that inflammatory expression increases gradually as epithelial cells progress through dysplasia to neoplasia [6].

Calprotectin is a cytoplasmic antimicrobial compound prominent in granulocytes, monocytes, and macrophages. It accounts for approximately $60 \%$ of the total protein of 
the cytosol. Release of calprotectin is most probably a consequence of cell disruption and death [7] and the compound is stable in stools for more than 7 days at different temperatures and is resistant to proteolysis even after transportation and storage [8]. Calprotectin can inhibit bacterial proliferation as a component of the innate immune response and through its iron-binding capacity [9]. Fecal calprotectin determination has been shown to be useful in diagnosis of a variety of inflammatory diseases of the gastrointestinal tract [10-14]; no data are available for colonic polyposis, however, even though it is a common disease of the colon. We therefore planned this prospective study to determine the significance of stool calprotectin concentrations in patients affected by colonic polyps.

\section{Methods}

Eligible patients eighteen year of age or older who underwent colonoscopy for the first time at the Department of Internal Medicine between February 2005 and February 2006 were enrolled. Patients in anticoagulant therapy, those treated with anti-inflammatory drugs [15], heavy alcohol drinkers [16], patients with rheumatoid arthritis, cystic fibrosis, acute bacterial infections [17], and the presence of known or suspected inflammatory bowel disease and colon cancer were excluded from the study. A stool specimen was obtained from each subject enrolled in the study three days before endoscopic examination and before any administered bowel preparation. Laboratory personnel were unaware of the clinical diagnoses or details of the patients' clinical histories. The stool specimens were stored at $-20^{\circ} \mathrm{C}$ and calprotectin was assayed within four weeks of collection. Calprotectin concentrations were measured by use of a commercial ELISA kit (Calprotectin ELISA Kit, Immundiagnostik, Bensheim, Germany) based on a two-site sandwich technique with two selected monoclonal antibodies which bind to human calprotectin. Two 100-mg samples of feces from a single stool sample from each participant were assayed, and the mean of the two measurements was recorded. According to the manufacturer, the reference range was $<15 \mu \mathrm{g} \mathrm{g}^{-1}$. The withinrun $\% \mathrm{CV}(n=20)$ was 9.1 at $10.7 \mu \mathrm{g} \mathrm{g}^{-1}$ and 4.2 at $22.2 \mu \mathrm{g} \mathrm{g}^{-1}$ and the between-run \%CV $(n=12)$ was 12.3 at $9.9 \mu \mathrm{g} \mathrm{g}^{-1}$ and 6.1 at $22.5 \mu \mathrm{g} \mathrm{g}^{-1}$; the detection limit of the test was $2.9 \mu \mathrm{g} \mathrm{g}^{-1}$. Colonoscopy was performed by a single experienced endoscopist (GG) using an Olympus colonoscope (CF-Q160Z I, Olympus Italia S.r.l., Segrate, Italy). The cecum was reached and photographed in each of the patients studied. The site and the number of polyps identified during insertion and withdrawal using the colonoscope were recorded.

\section{Ethics}

The study was approved by the Clinical Committee of the Department of Internal Medicine and all subjects gave verbal informed consent to participate in the study.

\section{Statistical analysis}

Results are reported as mean $\pm \mathrm{SD}$, median, range, and frequencies. The Shapiro-Wilk's test of normality and the Levene test for homogeneity of variance were applied: age ( $P=0.211$, and $P=0.234$, respectively) and BMI ( $P=0.090$, and $P=0.399$ respectively) did not require transformation and logarithmic transformation was applied to stool calprotectin values (before transformation: $P<0.001$, and $P=0.015$, respectively; after transformation: $P=0.083$, and $P=0.693$, respectively). The data were analyzed by one-way ANOVA (by applying the simple contrast for pairwise comparisons), the $\chi^{2}$ test, and Pearson's correlation. Statistical analysis was performed by use of the Statistical Package for the Social Sciences for Windows, version 13.0 (SPSS, Chicago, IL, USA), and a two-tailed $0.05 P$ level was considered to be statistically significant.

\section{Results}

\section{Patients}

Sixty-three consecutive patients (35 males, 28 females, mean age 60.3 years, range $39-78$ years) were enrolled in this study. The patients were divided into three groups according to final diagnosis. The first group (Polyposis) contained 26 patients $(41.3 \%)$ in whom a total of 43 polyps were found. A single polyp was found in sixteen patients $(61.5 \%)$ and two or more polyps were found in ten patients (38.5\%) (two polyps in five patients, three polyps in four patients, five polyps in one patient), thus the mean was $1.7 \pm 1.0$ polyps per patient. Polyp size was $8.1 \pm 9.0 \mathrm{~mm}$ with a median of $5 \mathrm{~mm}$ and the range was from 3 to $60 \mathrm{~mm}$. Twenty-five polyps were sessile $(58.1 \%)$, fifteen were flat $(34.9 \%)$, two were semipedunculate $(4.7 \%)$, and one was pedunculate $(2.3 \%)$. Ten of the polyps were in the ascending colon $(23.3 \%)$, thirteen in the transverse colon $(30.2 \%)$, three in the descending colon $(7.0 \%)$, twelve in the sigmoid colon $(27.9 \%)$, and the remaining five in the rectum $(11.6 \%)$. All the polyps were removed endoscopically and in no case was the histology indicative of cancer. The second group (Diverticulosis) contained seventeen patients $(27.0 \%)$ with asymptomatic diverticular disease 
and the third group (Normal) contained twenty subjects $(31.7 \%)$ with normal endoscopic appearance of the colon. The characteristics of the three groups of patients studied are reported in Table 1.

\section{Stool calprotectin}

Figure 1 shows the individual concentrations of fecal calprotectin in the three groups of patients studied. Significant differences were observed among the three groups $(P=0.007)$ studied. In particular, the stool calprotectin concentration was $17.4 \pm 24.5 \mu \mathrm{g} \mathrm{g}^{-1}$ for patients with colonic polyposis and this figure was significantly higher than that found for patients with diverticulosis (calprotectin $7.1 \pm 5.7 \mu \mathrm{g} \mathrm{g}^{-1} ; P=0.026$ ) and for subjects with normal endoscopic appearance of the colon (calprotectin $\left.6.0 \pm 5.8 \mu \mathrm{g} \mathrm{g}^{-1} ; P=0.003\right)$. Fecal calprotectin concentrations for patients with diverticulosis were similar to those for subjects with normal endoscopic appearance of the colon $(P=0.516)$.

The 16 patients with single polyp had stool calprotectin concentrations (mean $\pm \mathrm{SD} 20.1 \pm 29.7 \mu \mathrm{g} \mathrm{g}^{-1}$; median $10.7 \mu \mathrm{g} \mathrm{g}^{-1}$ range $1.0-117.7 \mu \mathrm{g} \mathrm{g}^{-1}$ ) similar to those with more than one polyp (mean $\pm \mathrm{SD} 13.2 \pm 12.7 \mu \mathrm{g} \mathrm{g}^{-1}$; median $10.3 \mu \mathrm{g} \mathrm{g}^{-1}$ range $\left.3.1-46.2 \mu \mathrm{g} \mathrm{g}^{-1} ; P=0.830\right)$. For these patients, after the exclusion of two patients (one with a pedunculate polyp and one with a semipedunculate polyp), the calprotectin fecal concentration was not significantly different for the eight patients with sessile polyps (mean \pm SD $27.5 \pm 41.3 \mu \mathrm{g} \mathrm{g}^{-1}$; median $7.6 \mu \mathrm{g} \mathrm{g}^{-1}$, range 3.1-117.7 $\mu \mathrm{g} \mathrm{g}^{-1}$ ) and the six patients with flat polyps (mean \pm SD $11.9 \pm 9.1 \mu \mathrm{g} \mathrm{g}^{-1}$; median $10.7 \mu \mathrm{g} \mathrm{g}^{-1}$, range $\left.1.0-23.5 \mu \mathrm{g} \mathrm{g}^{-1} ; P=0.556\right)$, and it was not significantly related to the size of the polyps ( $P=0.097$; Pearson's $r$ ).

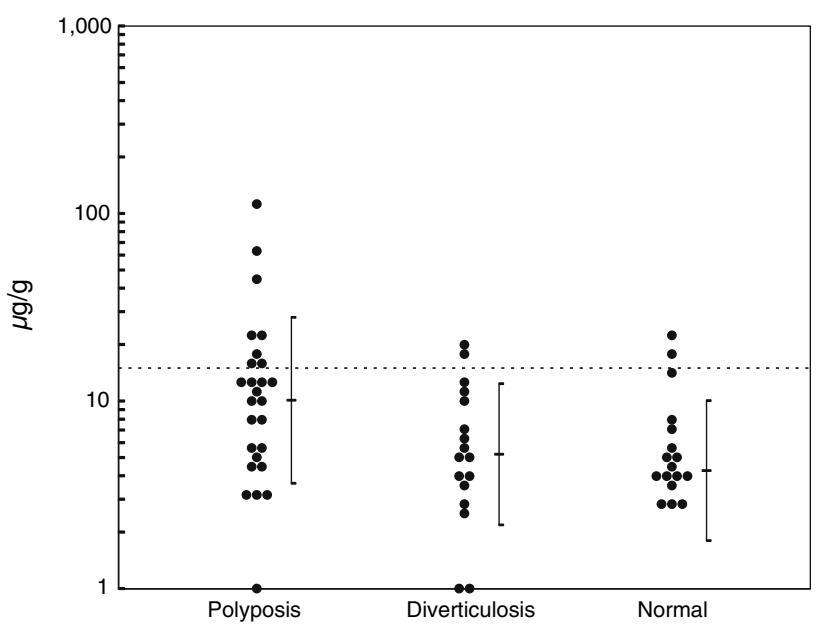

Fig. 1 Individual stool calprotectin concentrations for the three groups of patients studied: patients with colonic polyps (Polyposis), patients with asymptomatic diverticulosis (Diverticulosis), and subjects with normal endoscopic appearance of the colon (Normal). Mean \pm SD values are also reported. The horizontal dashed line indicates the upper reference limit

\section{Discussion}

It has been reported that colorectal cancer is associated with a local acute inflammatory reaction revealed by use of leukocyte scanning and histology [18]. Calprotectin, a stable neutrophil-specific marker, has also been shown to be a simple and sensitive marker of colorectal cancer [19, 20]. Information about colonic polyps is scarce, however. We undertook this study to explore the significance of fecal calprotectin in polypoid lesions of the colon. With regard to selection of patients, we found that those with a normal endoscopic appearance of the colon were younger and had a lower BMI than those with colonic polyposis and those

Table 1 Characteristics of the three groups of patients studied

\begin{tabular}{llll}
\hline & Polyposis $^{\mathrm{a}}(n=26)$ & Diverticulosis $^{\mathrm{a}}(n=17)$ & Normal $^{\mathrm{a}}(n=20)$ \\
\hline Sex & & & $P$ value \\
Males & $15(57.7 \%)$ & $11(64.7 \%)$ & $9(45.0 \%)$ \\
Females & $11(42.3 \%)$ & $6(35.3 \%)$ & $11(55.0 \%)$ \\
Age (years) & $61.9 \pm 7.6^{\mathrm{de}}$ & $62.8 \pm 10.0^{\mathrm{df}}$ & $56.2 \pm 10.6^{\mathrm{ef}}$ \\
BMI $\left(\mathrm{kg} \mathrm{m}^{-2}\right)$ & $25.9 \pm 3.9^{\mathrm{gh}}$ & $25.6 \pm 4.7^{\mathrm{gi}}$ & $23.0 \pm 3.2^{\mathrm{hi}}$ \\
\hline
\end{tabular}

Data are reported as mean \pm SD values and frequencies

a Polyposis: patients with colonic polyps; Diverticulosis: patients with asymptomatic diverticulosis; Normal: subjects with a normal endoscopic appearance of the colon

b $\chi^{2}$ test

c One-way ANOVA

Comparison between pairs of groups (simple contrasts were applied): Polyposis compared with Diverticulosis: ${ }^{\mathrm{d}} P=0.747,{ }^{\mathrm{g}} P=0.799 ;$ Polyposis compared with Normal: ${ }^{\mathrm{e}} P=0.042,{ }^{\mathrm{h}} P=0.013$; Diverticulosis compared with Normal: ${ }^{\mathrm{f}} P=0.033 ;{ }^{\mathrm{i}} P=0.044$ 
with asymptomatic diverticulosis. These findings are similar to literature reports regarding age [21,22] and BMI $[23,24]$.

With regard to the main objective of our study, evaluation of the significance of stool calprotectin concentrations in patients with colonic polyps, we found that this fecal index of inflammation was significantly higher for patients with colonic polyposis than for those with diverticulosis and those for subjects with a normal endoscopic appearance of the colon. This finding confirms-by analysis of calprotectin, a simple and easy-to-measure marker-that inflammatory expression progressively increases as epithelial cells progress from a normal colonic epithelium to one containing polyps [6]. The concentrations of fecal calprotectin for patients with a single polyp and those with multiple polyps were not significantly different, suggesting that the inflammatory response is not related to the number of the polypoid lesions. To evaluate whether calprotectin concentrations are related to the endoscopic appearance of polyps, we measured fecal calprotectin concentrations for patients with single polypoid lesions and found that the calprotectin concentration was not significantly for patients with sessile polyps and those with flat polyps; in the same group of patients we also found that calprotectin concentration was not related to the size of the polyps. These findings may suggest the inflammatory response is not related to the type or size of polypoid lesions but is probably related to the immunological status of the patient.

In conclusion, this study demonstrated that the presence of colonic polyps may increase stool calprotectin concentrations, which suggests that these colonic lesions should be suspected in cases of elevated stool calprotectin concentrations. Further studies are needed to confirm this initial promising observation.

\section{References}

1. Johns LE, Houlston RS (2001) A systematic review and metaanalysis of familial colorectal cancer risk. Am J Gastroenterol 96:2992-3003

2. Jorgensen OD, Kronborg O, Fenger C (1993) The funen adenoma follow-up study. Incidence and death from colorectal carcinoma in an adenoma surveillance program. Scan J Gastroenterol 28:869-874

3. Rex DK, Johnson DA, Lieberman DA (2000) Colorectal cancer prevention: screening recommendations of the American College of Gastroenterology. Am J Gastroenterol 95:868-877

4. O'Hare A, Fenlon H (2006) Virtual colonoscopy in the detection of colonic polyps and neoplasms. Best Pract Res Clin Gastroenterol 20:79-92

5. Ahmed FE (2003) Colon cancer: prevalence, screening, gene expression and mutation, and risk factors and assessment.
J Environ Sci Health C Environ Carcinog Ecotoxicol Rev 21:65-131

6. Gutfeld O, Prus D, Ackerman Z, Dishon S, Linke RP, Levin M, Urieli-Shoval S (2006) Expression of serum amyloid A, in normal, dysplastic, and neoplastic human colonic mucosa: implication for a role in colonic tumorigenesis. J Histochem Cytochem 54:63-73

7. Voganatsi A, Panyutich A, Miyasaki KT, Murthy RK (2001) Mechanism of extracellular release of human neutrophil calprotectin complex. J Leukoc Biol 70:130-134

8. Roseth AG, Fagerhol MK, Aadland E, Schjonsby H (1992) Assessment of the neutrophil dominating protein calprotectin in feces. A methodologic study. Scand J Gastroenterol 27:793-798

9. D'Inca R, Dal Pont E, Di Leo V, Ferronato A, Fries W, Vettorato MG, Martines D, Sturniolo GC (2006) Calprotectin and lactoferrin in the assessment of intestinal inflammation and organic disease. Int J Colorectal Dis epub ahead of print

10. Orlando A, Modesto I, Castiglione F, Scala L, Scimeca D, Rispo A, Teresi S, Mocciaro F, Criscuoli V, Marrone C, Platania P, De Falco T, Maisano S, Nicoli N, Cottone M (2006) The role of calprotectin in predicting endoscopic post-surgical recurrence in asymptomatic Crohn's disease: a comparison with ultrasound. Eur Rev Med Pharmacol Sci 10:17-22

11. Vermeire S, Van Assche G, Rutgeerts P (2006) Laboratory markers in IBD: useful, magic, or unnecessary toys? Gut 55:426431

12. Bremner A, Roked S, Robinson R, Phillips I, Beattie M (2005) Faecal calprotectin in children with chronic gastrointestinal symptoms. Acta Paediatr 94:1855-1858

13. Vieten D, Cairns P (2005) The role of calprotectin in the diagnosis of neonatal necrotising enterocolitis. Ir Med J 98:69

14. Roseth AG (2003) Determination of faecal calprotectin, a novel marker of organic gastrointestinal disorders. Dig Liver Dis 35:607-609

15. Tibble JA, Sigthorsson G, Foster R, Scott D, Fagerhol MK, Roseth A, Bjarnason I (1999) High prevalence of NSAID enteropathy as shown by a simple faecal test. Gut 45:362-6

16. Homann C, Christensen E, Schlichting P, Philipsen EK, Graudal NA, Garred P (2003) Ascites fluid and plasma calprotectin concentrations in liver disease. Scand J Gastroenterol 38:415-420

17. Ton H, Brandsnes, Dale S, Holtlund J, Skuibina E, Schjonsby H, Johne B (2000) Improved assay for fecal calprotectin. Clin Chim Acta 292:41-54

18. Saverymuttu SH, Maltby P, Batman P, Joseph AE, Maxwell D (1986) False positive localisation of indium-111 granulocytes in colonic carcinoma. Br J Radiol 59:773-777

19. Tibble J, Sigthorsson G, Foster R, Sherwood R, Fagerhol M, Bjarnason I (2001) Faecal calprotectin and faecal occult blood tests in the diagnosis of colorectal carcinoma and adenoma. Gut 49:402-408

20. Hoff G, Grotmol T, Thiis-Evensen E, Bretthauer M, Gondal G, Vatn MH (2004) Testing for faecal calprotectin (PhiCal) in the Norwegian Colorectal Cancer Prevention trial on flexible sigmoidoscopy screening: comparison with an immunochemical test for occult blood (FlexSure OBT). Gut 53:1329-1331

21. Kang JY, Dhar A, Pollok R, Leicester RJ, Benson MJ, Kumar D, Melville D, Neild PJ, Tibbs CJ, Maxwell JD (2004) Diverticular disease of the colon: ethnic differences in frequency. Aliment Pharmacol Ther 19:765-769

22. Souques M, Lassalle M, Guldner L, Asselain B, Barres D, Pavis C, Dubois G, Martin E, Flejou JF (2006) Colorectal polyps and cancers diagnosed by pathologists in Ile de France Region Crisapif-Petri Study. Gastroenterol Clin Biol 30:587-593 
23. Dobbins C, Defontgalland D, Duthie G, Wattchow DA (2006) The relationship of obesity to the complications of diverticular disease. Colorectal Dis 8:37-40

24. Betes M, Munoz-Navas MA, Duque JM, Angos R, Macias E, Subtil JC, Herraiz M, De La Riva S, Delgado-Rodriguez M,
Martinez-Gonzalez MA (2003) Use of colonoscopy as a primary screening test for colorectal cancer in average risk people. Am J Gastroenterol 98:2648-2654 